\section{Advances in the methodology of co- ventilation during a disaster}

\author{
Charlene Irvin Babcock 이, ', Lorenzo Paladino ${ }^{2,3}$
}

The study by Tonetti et $a l^{1}$ describes a potential configuration for the invasive ventilation of two adults on one ventilator ('co-venting'). This is a similar configuration to those previously published in 2006 by Neyman and Irvin (four test lungs on one ventilator), ${ }^{2}$ and evaluated both in 2008 by Paladino et $\mathrm{al}^{3}$ (using normal lungs in sheep, ventilating four on one ventilator) and again by Branson et $a l^{4}$ in 2012 (with different respiratory system compliance and airways resistance in four tested lungs on one ventilator). This concept was also explored using face masks (non-invasive ventilation) in two human volunteers for $10 \mathrm{~min}$ by Smith and Brown in 2009..$^{5}$ In 2017, Keven Menes used this previously evaluated 'splitting' of ventilators and implemented it during a mass shooting in Las Vegas, when a sudden influx of injured patients caused an acute ventilator shortage. ${ }^{6}$ This mass casualty event revealed its first successful use in humans (two patients on one ventilator), although this experience has not been published in a peerreviewed journal.

This research and proof of concept by Neyman, Irvin ${ }^{2}$ and Paladino et $a l^{3}{ }^{3}$ were not meant to endorse the use of co-venting on four patients exclusively. Rather the aim was to show the scalability of the procedure in a disaster. If four patients can be ventilated with one machine, the same approach can certainly be applied to two patients on a single ventilator. Indeed, the US Health and Human Services has released several documents pertaining to co-venting including the COVID-19 Task Force guidelines which described one potential method of co-venting if it were to become necessary. ${ }^{7}$

On 14 March 2020, a Youtube video was launched by one of the authors (CIB) showing the set-up for ventilating four test lungs on one ventilator, and also revealed the set-up for two test lungs on one ventilator. ${ }^{8}$ This information, along with the

\footnotetext{
${ }^{1}$ Department of Emergency Medicine, Ascension St John Hospital and Medical Center, Detroit, Michigan, USA ${ }^{2}$ Department of Emergency Medicine, State University of New York Downstate Medical Center, Brooklyn, New York, USA

${ }^{3}$ Department of Emergency Medicine, Kings County Hospital Center, Brooklyn, New York, USA

Correspondence to Dr Charlene Irvin Babcock, Department of Emergency Medicine, Ascension St. John Hospital and Medical Center, Detroit, MI 48374, USA; charlenebabcockmd@gmail.com
}

previously published articles regarding this process, ${ }^{23}$ was shared with physicians at various Italian universities by one of the authors (LP) in early March as they struggled with how to address the ventilator shortage. This led to the manuscript published by Tonetti et al, which shows in more detail the two patient on one ventilator configuration. ${ }^{1}$

There have been considerable recent advances and insight into this potential approach as the COVID-19 pandemic continues to challenge those managing patients needing ventilatory assistance with limited ventilator resources. While some societies have raised concern about the lack of human experience in diseased lungs (Menes use in humans had mostly normal lungs $)^{6}$ and recommend against it, ${ }^{9}$ other institutions have explored it as an option in dire circumstances and published their recommended methodology. ${ }^{10}$

Everyone agrees one patient on one ventilator will always be the gold standard. Use of one ventilator for two patients is clearly outside the manufacturer's recommendations and only appropriate in dire circumstances during a disaster. Understanding the background, parts needed, set-up configuration and implementation procedure options will assist those who may need this novel approach to expand ventilator options. We commend the authors of this study for further advancing documentation of this potential expansion of ventilator availability as a life-saving intervention during a disaster and hope the additional information we have provided may be informative.

Contributors Both authors contributed to the manuscript and edits.

Funding The authors have not declared a specific grant for this research from any funding agency in the public, commercial or not-for-profit sectors.

Competing interests None declared.

Patient consent for publication Not required.

Provenance and peer review Commissioned; internally peer reviewed.

Data availability statement No data are available. No data. is reported.

This article is made freely available for use in accordance with BMJ's website terms and conditions for the duration of the covid-19 pandemic or until otherwise determined by BMJ. You may use, download and print the article for any lawful, non-commercial purpose (including text and data mining) provided that all copyright notices and trade marks are retained.

(C) Author(s) (or their employer(s)) 2020. No commercial re-use. See rights and permissions. Published by BMJ.

Check for updates

To cite Irvin Babcock C, Paladino L. Thorax 2020;75:448.

Received 6 April 2020

Revised 7 April 2020

Accepted 8 April 2020

Published Online First 19 April 2020

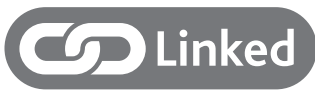

- http://dx.doi.org/10.1136/thoraxjnl-2020-214895

- http://dx.doi.org/10.1136/thoraxjnl-2020-214929

Thorax 2020;75:448.

doi:10.1136/thoraxjnl-2020-214967

ORCID iD

Charlene Irvin Babcock http://orcid.org/0000-00020157-7317

\section{REFERENCES}

1 Tonetti T, Zanella A, Pizzilli G, et al. One ventilator for two patients: feasibility and considerations of a last resort solution in case of equipment shortage. Thorax 2020;75:517-9.

2 Neyman G, Irvin CB. A single ventilator for multiple simulated patients to meet disaster surge. Acad Emerg Med 2006;13:1246-9.

3 Paladino L, Silverberg M, Charchaflieh JG, et al. Increasing ventilator surge capacity in disasters: ventilation of four adult-human-sized sheep on a single ventilator with a modified circuit. Resuscitation 2008;77:121-6.

4 Branson RD, Blakeman TC, Robinson BR, et al. Use of a single ventilator to support 4 patients: laboratory evaluation of a limited concept. Respir Care 2012;57:399-403.

5 Smith R, Brown JM. Simultaneous ventilation of two healthy subjects with a single ventilator. Resuscitation 2009;80:1087.

6 Menes K, Tintinalli J, Plaster L. How one LAS Vegas ED saved hundreds of lives after the worst mass shooting in U.S. history, 2017. Available: https://epmonthly. com/article/not-heroes-wear-capes-one-las-vegas-edsaved-hundreds-lives-worst-mass-shooting-u-s-history/ [Accessed 6 Apr 2020].

7 U.S. Public health service commissioned Corps, 2020. Available: https://www.hhs.gov/sites/default/files/ optimizing-ventilator-use-during-covid19-pandemic. pdf

8 Charlene Irvin Babcock. How to use one ventilator to save multiple lives. Available: https://www.youtube.com/ watch?v=uClq978oohY [Accessed 14 Mar 2020].

9 The Society of Critical Care Medicine, American Association for Respiratory Care, American Society of Anesthesiologists, Anesthesia Patient Safety Foundation, American Association of Critical-Care Nurses, American College of Chest Physicians. Joint statement on multiple patients per ventilator, 2020. Available: https://www. asahq.org/about-asa/newsroom/news-releases/2020/ 03/joint-statement-on-multiple-patients-per-ventilator [Accessed 6 Apr 2020].

10 Beitler JR, Kallet R, Kacmarek R, et al. Ventilator sharing protocol: Dual-Patient ventilation witha single mechanical ventilator for use during critical ventilator shortage, 2020.Available: https://protocols.nyp.org [Accessed 6 Apr 2020]. 